\title{
Comunicação, Resistência e Cidadania: As Festas Populares
}

Communication, resistence and citizenship: the popular celebrations

\section{Maria Nazareth Ferreira \\ Profa. de Comunicação da ECA/USP, pesquisadora do CNPq e dirigente do Cellac E-mail: nazarethferreira@uol.com.br}

Resumo

Estudo das festas populares, como objeto de conhecimento científico: como sistema de comunicação das classes subalternas, como produção cultural privilegiada para o estudo da identidade cultural, da construção da cidadania e do turismo cultural. Tanto pela relevância dos atos sociais que se desenrolam no âmbito das festas, como pelo significado social que as mesmas podem aportar para o fortalecimento da memória histórica e da resistência cultural das classes subalternas. Proposição metodológica para uma possivel teoria das festas populares.

Palavras-chave; Festas populares como objeto de estudo - Cidadania e participação - Identidade cultural e resistência - Turismo cultural - Comunicação e culturas subalternas.

As festas populares como objeto de estudo científico são relativamente recentes no Brasil, exceto pelos estudos sobre o Carnaval carioca. A maioria dos estudos sobre festas populares ora são de caráter antropológico ou sociológico, ora são meras descrições. No entanto, há uma vasta tradição de estudos europeus - principalmente italianos, franceses e alemães - nos quais as festas populares assumem status de objeto de estudos científicos e multidisciplinares.

Por outro lado, atualmente, com a expansão do turismo, em nível mundial, um dos assuntos mais explorados como consumo turístico são justamente as festas populares. Não somente na Europa ${ }^{1}$ - mas mesmo no Brasil, e em outros países da América Latina ${ }^{2}$-, essa opção tem sido uma alternativa para incrementar as economias locais das pequenas cidades marginalizadas pelo processo neoliberal, cuja natureza é privilegiar a produção para exportação, ignorando as economias de pequeno porte.

Diante desse quadro tem havido, principalmente no Brasil, uma crescente valorização das festas populares, como já foi apontado em outros projetos anteriores desenvolvidos pelo Centro de Estudos Latino-Americano sobre Cultura e Comunicação da USP, sob orientação desta autora.

Assim sendo, a proposta de aprofundar os estudos sobre essas manifestações das culturas subalternas poderá trazer algum subsídio para a construção de uma teoria das festas populares, não apenas como instrumento privilegiado para o entendimento dos fenômenos de comunicação e como "mercadoria" para a expansão do turismo, mas principalmente como portador de ações concretas na construção da cidadania e no fortalecimento de laços sociais e identitários.

As festas podem ser examinadas do ponto de vista da atividade lúdica, mas também como um acontecimento aglutinador da realidade das comunidades envolvidas, no sentido de avaliar seu potencial como formadora da
1 FERREIRA, Maria Nazareth. As Festas Populares na Expansão do Turismo: A Experiência Italiana. $2^{\mathrm{a}}$ Edição, revista e ampliada. São Paulo. Arteódiência, 2005.

2 Projetos Realizados pelo CELACC: Identidade Cultural e Cidadania: 0 potencial das cidades históricas para o Turismo, 2003. Cultura, Globalização e Turismo: a cultura subalterna como mercadoria, 1998. 
cidadania, da conscientização e da participação social, porque um dos elementos mais significativos no processo de realização da festa é a transformação do indivíduo comum em protagonista daquele evento.

Entretanto, o fenômeno festa tem também dois aspectos a serem examinados: como fator econômico, visto que tem dado excelentes resultados como "mercadoria" para a expansão do turismo, e como instrumento privilegiado para o entendimento dos fenômenos de comunicação das classes subalternas.

Com essa perspectiva é possível considerar o fenômeno "festa", que é praticado, desde épocas antigas até as mais recentes, por determinados conjuntos humanos, os quais, principalmente em regiões periféricas, têm sobrevivido ao impacto das mídias e dos processos predadores neoliberais. Essas práticas, ultrapassando a barreira do tempo, enfrentando diversas dificuldades de diferentes aspectos, vivenciando intensos processos de aculturação, de sincretismo e mesmo de proibições, prevalecem até a atualidade numa reafirmação da cultura como força propulsora de processos civilizatórios integradores e, também, como poderoso instrumento de comunicação.

Para compreender o fenômeno "festa" é necessário realizar uma operação de análise científica, tendo em vista a desmesurada dimensão cultural que assume numa sociedade.

Do ponto científico, a festa é um singular objeto de estudo, contemplado por especialistas de todas as correntes. É tão significativa para o homem, como ser comunicativo e social, que se pode

${ }^{3}$ LANTERNARI, Vittorio. Festa, carisma, apocalisse. Palermo: Sellerio, 1989. pp.25 e seguintes.

${ }^{4}$ Idem, ibidem. da cultura, é um espelho no qual o ser humano se reflete, buscando respostas para sua condição de precariedade frente à vida ${ }^{3}$

Antes da invenção dos modernos meios de comunicação, as festas constituíam a mais importante atividade pública: eram os momentos centrais dessa atividade, funcionando como autênticos sistemas de comunicação entre a comunidade e entre esta e os visitantes que participavam do evento. Para a comunidade, eram momentos de afirmação da identidade coletiva, mediante os quais o indivíduo tomava consciência de seu "pertencimento" a determinado grupo, assumindo o papel de protagonista de sua própria história. A festa era também um "lugar simbólico", no qual eram veiculados os valores e as crenças do grupo, transformando-se, portanto, no principal lugar onde afloravam os conflitos de significado na disputa pelo monopólio da informação e, até mesmo, do controle social.

A festa deve ser vista como um conjunto de atos cerimoniais de caráter coletivo pela sua colocação dentro de um tempo delimitado, tido como "diverso" da cotidianidade. Em qualquer tipo de festa, o grupo ou a comunidade interrompe o tempo ordinário para entrar, coletivamente, na dimensão de um tempo carregado de implicação cultural e de conotação psíquica própria, diferente daquele tempo ordinário ou cotidiano. Esse aspecto poderá ser identificado nas festas populares de qualquer região. Os protagonistas dos eventos festivos, poderão estar - estarão vivenciando outro momento, diferente de sua cotidianidade - como já foi observado em outro estudo realizado -, não estando apenas interpretando, mas vivendo uma experiência cultural de outra ordem.

De fato, o tempo festivo se 
coloca, com respeito ao tempo ordinário ou cotidiano, como seu complemento dialético, como o ser em relação ao fazer - eu sou (a materialidade do ser, a força de sua existência social) - e, na festa religiosa, como o sagrado em relação ao profano. Fazer festa significa colocar-se diante do espelho, procurando a si mesmo e à sua identidade; é buscar reencontrar as garantias histórico-culturais, reconfirmando-as na força da representação, no ato comunicativo e comunitário. Essa ação de resgatar a própria identidade é fundamental para encontrar-se a si mesmo e recuperar um equilíbrio que pode estar ameaçado ${ }^{4}$. Esse resgate, entretanto, é um ato conflitivo, porque significa incorporar novos valores àqueles tradicionais. No entanto, esse conflito, longe de ser algo prejudicial, é uma experiência salutar, porque essa renovação, dialeticamente, enriquece a identidade cultural da comunidade, pois, ao incorporar novos valores culturais, atesta o caráter cumulativo e dinâmico da experiência humana na construção da cultura.

Como nota F. Remotti, o processo de construção da identidade traz à baila, inevitavelmente, um processo de relação social conflitivo: "Si puó affermare tranquillamente che nessuna societá é mai riuscita per fortuna - a costruire e mantenere la propria identitá sotto forma di uma sfera compatta e inattaccabile (...) Tutte le culture sono il prodotto di interazioni, di scambi, di influssi. provenienti da altrove... le culture non sono pure. Ogni società há a da fare $i$ conti con l'alterità..." 5

Essa necessidade de reencontrar e re-confirmar periodicamente a própria identidade é o correspondente psicológico da condição de precariedade que



acompanha as fases mais comuns da vida e da qual o homem assume consciência por meio do acúmulo de experiências e das atividades cotidianas.

A dialética entre o ser e ofazer atualmente se coloca como uma força, uma necessidade de reação ao mundo contemporâneo, onde os contornos identitários estão cada vez mais indefinidos; hoje, mais que nunca, se procura, com renovado afã, delimitar as fronteiras entre o eu e o outro; nesse sentido, as festas podem aportar significativos elementos, pois atravessam a barreira do tempo para buscar, num passado mais ou menos remoto, os signos de sua identidade. É, provavelmente, por essa razão que algumas festas, depois de haver caído em desuso, voltaram há pouco tempo a ser realizadas, não apenas como reafirmação da identidade para uso interno, mas também como fortalecimento dessa mesma identidade em face do consumo turístico.

A festa reproduz simbolicamente a condição do caos mítico primordial, quando promove a anulação do presente. Assim, a festa

\footnotetext{
${ }^{5}$ REMOTTI, F. Contro l'identità. Bari: Laterza, 1996.
} 



contraditória potencialização entre conservação e criatividade cultural. De um lado, empurra o indivíduo à fuga, à evasão da realidade banal, do cotidiano, para mergulhá-lo no momento mágico da festa, que é também o momento do sagrado e do caos primordial. Essa evasão é provocada pelas técnicas que constituem a parte essencial da instituição festiva: o riso, o jogo, a dança, a música, a alegria, o descontrole orgiástico, o dramático etc. De outro lado, o clima festivo abre uma possibilidade psicológica e fornece uma carga de energia psíquica que permite ao indivíduo enfrentar com vigor e independência criativa as batalhas do cotidiano ${ }^{6}$. No caso de algumas festas principalmente aquelas das classes subalternas -, é necessário não perder de vista um de seus objetivos principais: o de implementar o turismo em suas localidades, o que, por si só, é um elemento positivo do ponto de vista da comunidade.

Entretanto, um aspecto a ser destacado é que a análise das festas populares, no âmbito das ciências humanas - e mesmo nas ciências da comunicação -, é um importante instrumento científico para a ${ }^{6}$ LANTERNARI, Vittorio. Op. cit., pp. 27, 30-31. compreensão da contemporaneidade, porque estabelece relações diretas com a problemática da identidade cultural em face das investidas repressivas da comunicação midiática e, por conseguinte, com a expansão sem precedentes da atividade turística predatória, em escala planetária.

O atual processo de globalização propagado pelas midias encabeça mecanismos de alienação que estão presentes no caráter sedutor das mercadorias e das práticas de consumo em geral, pois preconizam a padronização e a uniformização de hábitos, valores e ideologias, interferindo fortemente nos processos identitários das pequenas comunidades, mais expostas ao turismo massificado.

É em defesa de outra forma de turismo - o turismo cultural - que uma proposição para o estudo científico das atividades festivas das classes subalternas tem sentido.

O estudo das festas implica na exaltação dos atributos históricos e culturais de um determinado território, evidenciando os processos civilizatórios que se revelam como integradores de uma determinada comunidade. Compreende-se, neste sentido, uma localidade específica como um locus provido de traços identitários presentes na história coletiva, mas também nas individualidades em seu sentido pleno, dialético, e não no sentido liberal-burguês.

Neste exame da festa das classes subalternas como categoria da cultura, cabe abordar dois aspectos que são significativos para a compreensão de sua validade como objeto de estudo.

O primeiro deles é a capacidade que a festa tem de trazer para a atualidade, desde longínquas épocas, as experiências culturais vivenciadas por determinada população; o segundo aspecto refere-se ao fato de que, mesmo contrariando as práticas 
intencionalmente concebidas no momento da festa, os usos e os costumes mais profundos vivenciados pela cotidianidade $\mathrm{e}$ entranhados no inconsciente afloram, mostrando a verdadeira face de um povo, de uma comunidade moldada através da cultura.

Desses dois aspectos existentes no fenômeno "festa" é possível extrair os elementos de identidade mais significativos de uma determinada cultura, bem como entender esses elementos como um sistema de comunicação que permite ao observador avaliar como o passado e o presente se articulam no interior dessa cultura e as várias formas de identidades que são, ao mesmo tempo, re-significadas, assumindo novos aspectos.

É necessário salientar que a festa estabelece uma relação complexa com a realidade; não é uma simples reprodução ou inversão de sentido; a festa recolhe experiências que normalmente são vivenciadas em separado, e acrescenta sentido àquilo que no cotidiano é percebido como descontinuidade. Neste sentido, a festa estabelece uma relação com $o$ seu contexto, ao menos, de dois modos: como inversão, na medida em que o tempo mítico inverte a realidade cotidiana, e como reprodução do mundo cotidiano; através da performance; a reprodução permite um acréscimo de sentido que pode ser o valor da reconstrução da identidade ameaçada e um aumento da percepção das relações sociais (a importância do sentimento de pertencer a determinada comunidade, cujas raízes são comuns, como nas festas populares), onde o processo comunicativo-cultural é dado através da performance, capaz de atrair a atenção de indivíduos estranhos à festa, como é o caso dos turistas.

À dialética entre reprodução/ inversão junta-se a dialética entre tradição/inovação, indispensável elemento dinâmico dos processos culturais. Por outro lado, a dialética entre tradição/inovação, apesar de ser um elemento interno à festa, num sentido mais amplo, reconduz - como a dialética entre a reprodução/ inversão - à relação entre o festivo $\mathrm{e}$ o cotidiano. Compreende outro conjunto de elementos interativos, de modificação, de sincretismo e de criatividade, os quais constituem o produto visível no interior da festa; do dinamismo e das relações que se desenvolvem entre o contexto e a festa em si mesma. Nas festas das classes subalternas, a relação tradição/inovação (repetiçãoinvenção) poderá ser visível para o observador e também para os participantes - que com seus comentários indicam que a festa.é a mesma de cada ano, mas é diferente daquela anterior. Essa relação constitui, além de um forte elemento de dinamismo, um índice de vitalidade do fenômeno festivo.

No exame de uma festa popular é possível observar pelo menos três componentes básicos: a preparação, a execução (conjunto de atividades mais ou menos tradicionais, ritualísticas e formalizadas) e a ideologia presente na festa (isto é, o conjunto de símbolos, valores e crenças que, explícita ou implicitamente, são repetidos pela festa).

A ideologia, representada também pelos dois outros elementos, juntamente com os conceitos de reprodução/inversão e tradição/ inovação, reproduz a relação social entre festa e contexto e entre tempo festivo e tempo cotidiano ${ }^{7}$.

É possível afirmar que a ideologia que permeia a organização e a instituição das festas permite identificar como motivação a necessidade de reafirmar o elo
${ }^{7}$ GIGLIA, Angela. Clientelismo $e$ cultura popolare tradizionale: la festa. In: Signorinelli, Amalia. Chi può e chi aspetta i giovani clientelismo in una area interna del Mezzogiorno. Napole: Liguori, 1984, pp. 247-259. 
cultural que liga a atualidade brasileira e hispano-americana ao seu passado, como tentativa de reviver uma memória histórica ameaçada pelas rápidas transformações da realidade cotidiana. A insistência em buscar no mais longínquo passado as raízes do presente poderá estar visível na maneira como esse passado está resignificado e simbolizado nos mínimos detalhes da estética das festas examinadas em estudos exploratórios já realizados.

Outro ponto a ser ressaltado é que para qualquer tipo de análise do fenômeno festivo, se o objetivo é compreender a estrutura, a função e o seu significado, não se pode prescindir de dois componentes básicos:

1) o sentimento da festa: o que faz com que a festa exprima uma atmosfera intensamente participativa, densa de conotação simbólica e mítica, desenvolvendo uma função imediata e coletivamente catártica ${ }^{8}$;

2) a institucionalização da festa: cada festa comporta uma organização comunitária e uma regulamentação da parte do grupo festivo, que é mais ou menos amplo ou complexo. Neste componente organizacional, ao lado do elemento organizativocomunitário entra o quadro de referência ideológico anteposto à festa e que, segundo o caso, se refere a um mito de origem ritual ou simbolicamente reatualizado, à lenda de fundamentação de um culto; à imagem de um santo cristão; a um momento crítico da existência ou a um evento histórico, social ou político, que deve ser comemorado e reevocado, para renovar o impulso de vencer os percalços da cotidianidade através do fenômeno festivo ${ }^{9}$

Nas festas das classes subalternas podem ser examinadas as possibilidades da materialização dos conceitos de reprodução/ inversão (na medida em que a reprodução do tempo mítico inverte a realidade cotidiana) e também do conceito de tradição/inovação (na medida em que cada festa é, ao mesmo tempo, igual e diferente da anterior). Igualmente, pode-se observar se a reprodução da relação social entre a festa e o seu contexto (na medida em que a festa se fundamenta e se corresponde com uma determinada realidade histórica concreta) e entre o tempo festivo e o tempo ordinário ou cotidiano, na medida em que o tempo festivo é reflexo em positivo do tempo cotidiano, não sendo nunca a sua negação; positivo porque, nesse caso, o tempo cotidiano é idealizado e mitificado.

A partir destas considerações de caráter metodológico, será possível argumentar que a cultura desenvolvida pelas classes subalternas desde o período colonial brasileiro e hispano-americano, baseada na herança cultural de europeus, negros e índios, percorreu os séculos, chegando até a atualidade, modificando-se, porque é viva, mas mantendo o seu elo identitário; que esse fenômeno que atualmente torna possivel reconhecer e fortalecer a identidade nacional cultural é conseqüência do ato festivo, renovador e re-atualizador das práticas culturais dessas populações. Todos esses elementos poderão ser atualmente observados em qualquer festa que se examine, seja religiosa ou profana, porque fazem parte de um complexo comunicacional composto por textos, músicas, danças, imagens, oralidade, 
crenças, costumes e toda a sorte de práticas culturais, reafirmando aquela noção de que comunicação é cultura. Esses componentes poderão estar atualmente presentes nas festas, principalmente com o objetivo de atrair a atenção do crescente mercado turístico. Entretanto, ao expor a cultura, a memória histórica, os usos e os costumes dos povos, as festas das classes subalternas poderão subverter as propostas do turismo predatório, transformandoo em uma opção cultural, a qual tanto poderá beneficiar o próprio turista como, principalmente, as comunidades envolvidas em tal atividade.

\section{Abstrac}

In this text author proposes the study of popular celebrations as communication systems and as cultural productions that contribute for the construcion of group identities, citizenship and cultural tourism. Its social importance is due to the possibility of strenghtening the collective memory and popular resistenceto mass culture.

Keyword: popular celebration, culture, identity.

\section{Referência}

BAKHTIN, Mikhail, A cultura popular na Idade Média e no Renascimento: o contexto de F. Rabelais. São Paulo:Hucitec e Brasilia:Unb, 1999.

FERREIRA,M.N. As festas populares na expansão do turismo: a experiência italiana. $2^{\mathrm{a}}$. edição revista e ampliada. São Paulo, Arte\&Ciência, 2005.

GIGLIA, Ângela. Clientelismo e cultura popolare tradizionale: la festa. Napole: Liguori, 1984.

LANTENARI, Vittorio. Festa, carisma, apocalisse. Palermo: Sellerio, 1989.

REMOTTI, F. Contro l'identità. Bari: Laterza, 1996. RIVERA, Annamaria. II mago, il santo, la morte, la festa. Forme religiose nella cultura popolare.Bari: Dédalo, 1988.

VACCAI, G. Lê feste de Roma ântica: miti, riti, costumi. Roma: Mediterranee, 1986.

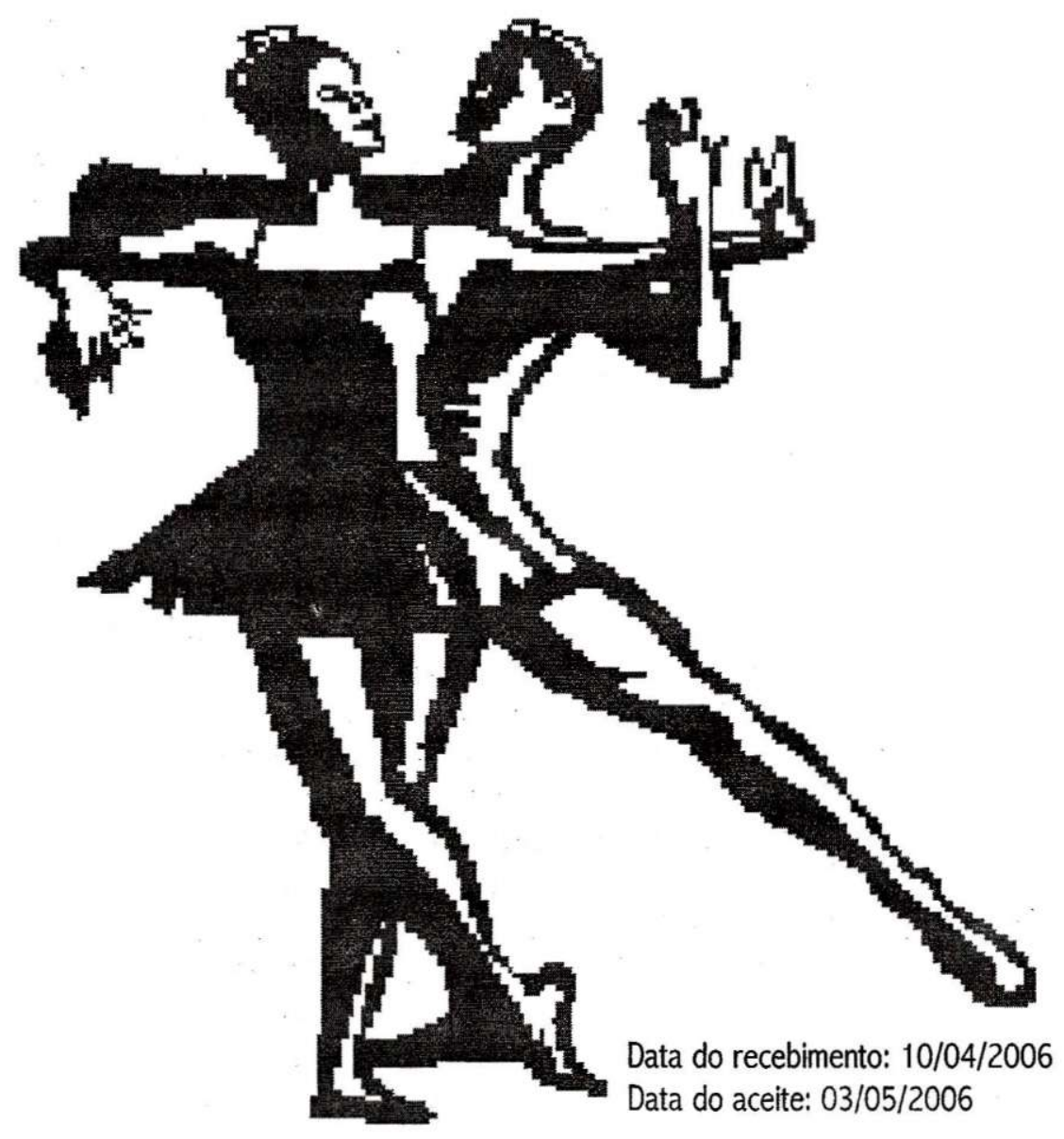

Maria Nazareth Ferreira. Comunicação, Resistência e Cidadania: As Festas Populares. Comunicação e Informação, V 9, nº 1: pág 111-118 - jan/jun. 2006. 